\title{
Effect of a Multidomain Lifestyle Intervention on Estimated Dementia Risk
}

\author{
Alina Solomon ${ }^{\mathrm{a}, \mathrm{b}}$, Ron Handels ${ }^{\mathrm{c}, \mathrm{d}, \mathrm{e}}$, Anders Wimo $^{\mathrm{e}}$, Riitta Antikainen ${ }^{\mathrm{f}, \mathrm{g}, \mathrm{h}}$, Tiina Laatikainen ${ }^{\mathrm{i}, \mathrm{j}, \mathrm{k}}$, \\ Esko Levälahti ${ }^{i}$, Markku Peltonen ${ }^{\mathrm{i}}$, Hilkka Soininen ${ }^{\mathrm{a}, 1}$, Timo Strandberg ${ }^{\mathrm{f}, \mathrm{m}}$, Jaakko Tuomilehto $^{\mathrm{i}, \mathrm{n}, \mathrm{o}}$, \\ Miia Kivipelto ${ }^{\mathrm{a}, \mathrm{b}, \mathrm{j}, \mathrm{p}}$ and Tiia Ngandu $\mathrm{u}^{\mathrm{b}, \mathrm{i}, *}$ \\ a Institute of Clinical Medicine/Neurology, University of Eastern Finland, Kuopio, Finland \\ ${ }^{\mathrm{b}}$ Karolinska Institutet, NVS, Division of Clinical Geriatrics, Solna, Stockholm, Sweden \\ ${ }^{\mathrm{c}}$ Alzheimer Centre Limburg, School for Mental Health and Neuroscience, Faculty of Health, Medicine and Life \\ Sciences, Maastricht University, Maastricht, The Netherlands \\ ${ }^{\mathrm{d}}$ Department of Psychiatry and Neuropsychology, Maastricht University, Maastricht, The Netherlands \\ ${ }^{\mathrm{e}}$ Karolinska Institutet, NVS, Division of Neurogeriatrics, Stockholm, Sweden \\ ${ }^{\mathrm{f}}$ Center for Life Course Health Research, University of Oulu, Oulu, Finland

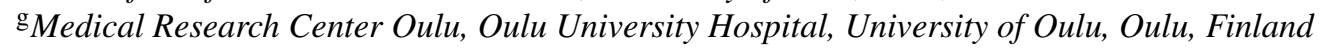 \\ ${ }^{\mathrm{h}}$ Oulu City Hospital, Oulu, Finland \\ ${ }^{\mathrm{i}}$ Department of Public Health and Welfare, Finnish Institute for Health and Welfare, Helsinki, Finland \\ ${ }^{\mathrm{j}}$ Institute of Public Health and Clinical Nutrition, University of Eastern Finland, Kuopio, Finland \\ ${ }^{\mathrm{k}}$ Hospital District of North Karelia, Joensuu, Finland \\ ${ }^{1}$ Neurocenter, Department of Neurology, Kuopio University Hospital, Kuopio, Finland \\ ${ }^{\mathrm{m}}$ University of Helsinki and Helsinki University Hospital, Helsinki, Finland \\ ${ }^{\mathrm{n}}$ Department of Public Health, University of Helsinki, Helsinki, Finland \\ ${ }^{\circ}$ National School of Public Health, Madrid, Spain \\ ${ }^{\mathrm{p}}$ Ageing Epidemiology Research Unit, School of Public Health, Imperial College London, London, \\ United Kingdom
}

Accepted 27 May 2021

Pre-press 17 June 2021

\begin{abstract}
We investigated the effect of a multidomain lifestyle intervention on the risk of dementia estimated using the validated CAIDE risk score (post-hoc analysis). The Finnish Geriatric Intervention Study to Prevent Cognitive Impairment and Disability (FINGER) is a 2-year randomized controlled trial among 1,260 at-risk older adults (60-77 years). Difference in the estimated mean change in CAIDE score at 2 years in the intervention compared to the control group was -0.16 (95 $\% \mathrm{CI}-0.31$ to 0.00$)(p=0.013)$, corresponding to a relative dementia risk reduction between $6.04-6.50 \%$. This could be interpreted as a reflection of the prevention potential of the intervention.
\end{abstract}

Keywords: Clinical trial, dementia, dementia risk score, lifestyle intervention, prevention

\footnotetext{
${ }^{*}$ Correspondence to: Tiia Ngandu, Population Health Unit, Department of Public Health and Welfare, Finnish Institute for Health and Welfare (THL), P.O. Box 30, 00271 Helsinki, Finland. Tel.: +358 29 5247716; E-mail: tiia.ngandu@thl.fi.
}

\section{INTRODUCTION}

Preventing dementia is a major public health priority [1]. Early identification of at-risk individuals is essential for effective preventive strategies. Several dementia risk algorithms have been developed based on various combinations of risk factors, often 
non-modifiable (e.g., age, sex, genetics) [2]. However, in addition to quantifying dementia risk, it is important to estimate prevention potential, i.e. the "room for risk reduction" with preventive interventions. Risk scores including modifiable factors (e.g., lifestyle, vascular, or metabolic) may be particularly useful for this purpose.

The Finnish Geriatric Intervention Study to Prevent Cognitive Impairment and Disability (FINGER) was the first large, longer-term randomized controlled trial to report significant benefits on cognition [3], health-related quality of life [4], disability [5], and multimorbidity [6] for a 2-year multidomain lifestyle intervention among 1,260 older individuals with elevated dementia risk. Here we report post-hoc analyses of intervention effects on change in the Cardiovascular Risk Factors, Aging and Dementia (CAIDE) Dementia Risk Score. The CAIDE score is a validated tool for estimating dementia risk based on age, sex, education, systolic blood pressure, body mass index, serum total cholesterol, and physical activity $[7,8]$, and it was used to select at-risk participants to the FINGER trial.

\section{METHODS}

The FINGER trial (ClinicalTrials.gov NCT 01041989) protocol [9], recruitment [10], and primary results [3] have been previously reported. FINGER is a multicenter study conducted in 6 centers in Finland. It was approved by the Coordinating Ethics Committee of the Hospital District of Helsinki and Uusimaa. Participants gave written informed consent.

Participants were recruited from previous population-based observational studies [10]. Eligibility criteria were: age 60-77 years; CAIDE Dementia Risk Score $\geq 6$ points (for screening purpose calculated based on data from previous surveys, up to 40 years before the trial); and at least one cognitive test criterion: the Consortium to Establish a Registry for Alzheimer's Disease (CERAD) [11, 12] Word List Memory task ( 10 words $x 3$ ) $\leq 19$ words, or CERAD Word List Recall $\leq 75 \%$, or Mini-Mental State Examination (MMSE) [13] $\leq 26 / 30$ points. Exclusion criteria were: dementia; MMSE $<20$ points; conditions affecting safe participation or preventing co-operation; and coincident participation in another trial.

Between September 7, 2009 and November 24, 2011, 2,654 individuals were screened for eligibility, and 1,260 were randomized 1:1 into the intensive multidomain intervention or regular health advice (i.e., control) group. Computer-generated randomization was done in blocks of four individuals at each site. Outcome assessors were blinded to allocation and not involved in the intervention. The control group received regular health advice. The intervention group received nutritional advice (individual and group sessions led by study nutritionists), physical exercise program supervised by study physiotherapists at the gym, cognitive training (individual computer-based training, and group sessions led by study psychologists), and management of metabolic and vascular risk factors [9]. The intervention was completed in February 2014.

Risk factors included in the CAIDE score are based on data from population register (age, sex), self-reported questionnaires (education, physical activity), measurements by the study nurse (systolic blood pressure, body mass index), and laboratory analyses (serum total cholesterol).The scoring system has been reported and validated previously [7, 8]. CAIDE Dementia Risk Score was calculated using data from the FINGER baseline, 12- and 24-month visits. In addition, $A P O E \varepsilon$ genotype was assessed [14]. $T$-test or $\chi^{2}$ test was used for baseline comparisons between intervention and control groups. Mixed effects regression models with maximum likelihood estimation were used to analyze change in CAIDE score as a function of randomization group, time, and group $x$ time interaction. All participants with CAIDE score available from at least one time point were included in the main analysis (intention-to-treat) $(n=1,254,99.5 \%)$. Sensitivity analyses were conducted including only participants with CAIDE score data at all time points $(n=1,030)$. Potential effect modification by other variables (baseline age, continuous; sex; or presence of at least one $A P O E \varepsilon 4$ allele) was investigated by adding the group $\mathrm{x}$ time $\mathrm{x}$ variable interaction to the model, together with the main variable effect and variable $\mathrm{x}$ time and variable $\mathrm{x}$ group interactions.

Analyses were adjusted by study site. Level of significance was set to $p=0.05$ in all analyses; we also report three-way interactions with $p<0.10$. Stata software version 14 was used.

\section{RESULTS}

Intervention and control groups were not significantly different in sociodemographic characteristics, 
Table 1

Baseline characteristics

\begin{tabular}{|c|c|c|c|c|}
\hline & $\begin{array}{l}\text { Number of } \\
\text { participants }\end{array}$ & $\begin{array}{c}\text { Intervention } \\
\text { group }(N=631)\end{array}$ & $\begin{array}{l}\text { Control group } \\
(N=629)\end{array}$ & $p$ \\
\hline Age at baseline, $\mathrm{y}$ & 1260 & $69.5(4.7)$ & $69.2(4.7)$ & 0.26 \\
\hline Women, $N(\%)$ & 1260 & $286(45.3)$ & $302(48.0)$ & 0.34 \\
\hline Education, y & 1258 & $10.0(3.5)$ & $10.0(3.4)$ & 0.94 \\
\hline Body mass index & 1251 & $28.3(4.5)$ & $28.1(4.9)$ & 0.44 \\
\hline Systolic blood pressure, $\mathrm{mmHg}$ & 1251 & $140.2(16.6)$ & $140.0(15.7)$ & 0.77 \\
\hline Physical inactivity, $N(\%)$ & 1247 & $189(30.2)$ & $175(28.1)$ & 0.41 \\
\hline APOE4 carrier, $N(\%)$ & 1175 & $189(32.0)$ & $200(34.2)$ & 0.43 \\
\hline Baseline CAIDE score & 1233 & $7.9(1.8)$ & $7.8(1.9)$ & 0.69 \\
\hline
\end{tabular}

Values are mean (SD) or $N(\%)$. The CAIDE Dementia Risk Score was calculated based on a combination of age, sex, education, systolic blood pressure, body mass index, total cholesterol and physical activity, as previously described [7].

vascular and lifestyle factors, medical history, cognitive performance (as previously described [3]), or CAIDE score (Table 1) at baseline. 1,254 (99.5\%) participants had CAIDE score data from at least one trial visit.

The estimated mean change in CAIDE score in the intervention and control group during the trial is shown in Fig. 1. Between-group difference was significant ( $p=0.013$ for the group $\times$ time interaction). Estimated mean change in CAIDE score at 2 years was -0.15 (95\% CI -0.26 to -0.04$)$ in the control and $-0.31(95 \% \mathrm{CI}-0.42$ to -0.20$)$ in the intervention group, with between-group difference $-0.16(95 \% \mathrm{CI}$ -0.31 to 0.00$)$. The estimated between group difference in mean change in CAIDE score at year 1 was -0.22 (95\% CI -0.37 to -0.07 ). Results remained unchanged in sensitivity analysis (participants with CAIDE score data at all 3 time points).

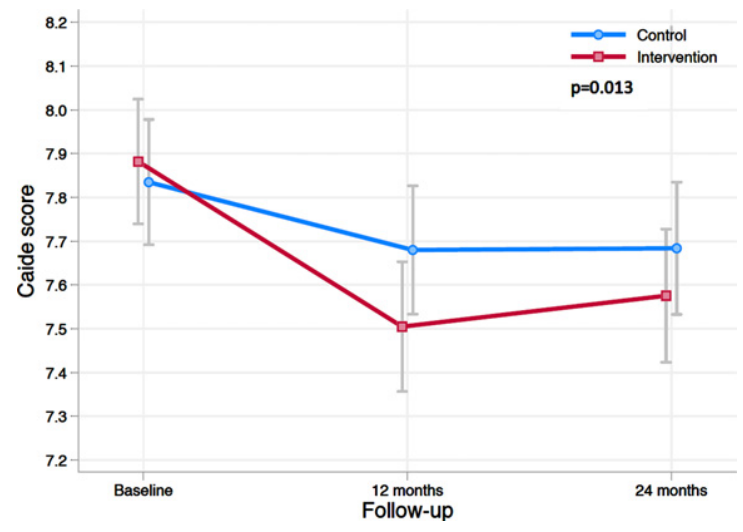

Fig. 1. Change in CAIDE Dementia Risk Score during the 2-year intervention. The figure shows estimated means of CAIDE score at baseline, 12 and 24 months (lower scores indicate lower risk for dementia). Error bars are CIs. Mixed-model repeated-measures analysis was used to assess between-group differences (randomization group $\times$ time interaction) in change from baseline to 24 months.
The intervention benefit on CAIDE score change tended to be more pronounced among women than men $(p=0.098$ for the randomization group $\mathrm{x}$ time $\mathrm{x}$ sex interaction). The 2-year estimated betweengroup difference for men was $-0.03(95 \% \mathrm{CI}-0.24$ to 0.19 ) and for women -0.31 (95\% CI -0.54 to -0.08$)$. There were no differences in attrition between men and women.

No significant differences were found by age or $A P O E \varepsilon 4$ carrier status $(p>0.32)$.

To translate the intervention-related change in CAIDE score into estimates of dementia risk reduction, we used a previously reported formula for calculating 20-year dementia risk in middle-aged individuals [7]:

$\mathrm{P}($ dementia $)=\frac{e^{(-7.406+0.796+0.401 * \mathrm{SCORE})}}{1+e^{(-7.406+0.796+0.401 * \mathrm{SCORE})}}$

where $\mathrm{SCORE}_{\text {control }}$ was the baseline CAIDE score (mean 7.86 for all participants) minus 1 point for age to reflect a middle-aged population; and SCORE $_{\text {intervention }}$ was $\mathrm{SCORE}_{\text {control }}$ minus 0.16 (estimated 2-year intervention-related decrease in CAIDE score). With a control group 20-year risk of $2.07 \%$, and an intervention group risk of $1.94 \%$, their ratio was 0.94 . This indicated a relative risk reduction of $6.09 \%$. Without the age adjustment, the relative risk reduction was $6.04 \%$. Similar calculations using the observed 2-year difference in CAIDE score change between intervention and control groups $(-0.17)$ with and without age adjustment resulted in a relative risk reduction between $6.44 \%$ and $6.50 \%$.

\section{DISCUSSION}

In the FINGER trial, there was a significant beneficial intervention effect on reducing estimated dementia risk measured by the CAIDE score. This 
effect tended to be more pronounced in women. As the intervention was more intensive during the first year, the reduction in CAIDE score was also more pronounced during the first year followed by maintenance of the risk score reduction during the second year.

These post-hoc analyses could be interpreted as a reflection of the prevention potential of the intervention. The FINGER intervention was started early, in at-risk individuals without substantial cognitive impairment [3], and therefore incident dementia was not a feasible outcome after 2 years. For several reasons, the estimates presented here may not reflect the actual magnitude of dementia risk reduction: The CAIDE Dementia Risk Score is based on simple cut-offs for risk factors, restricting its sensitivity to change over time. While it also includes nonmodifiable risk factors, the intervention effect is less likely to be overestimated since risk estimates are adjusted for such factors. Also, the CAIDE score was developed as the first midlife risk score for estimating dementia risk 20 years later and was used to select FINGER participants based on pre-trial midlife data. In addition, the FINGER control group received a program of regular general health advice as per national guidelines, leading to more conservative intervention effect estimates than a "do-nothing" control group. Although the CAIDE score was also reduced in the control group (a benefit that may at least partly be explained by "trial effect", regression to the mean or other factors) $[15,16]$, the reduction was significantly greater in the intervention group.

The intervention effect on the CAIDE score tended to be more pronounced among women, although the test of interaction was not significant. Given the limited sample size it is not possible to provide reliable estimates separately for men and women. Hopefully larger trials and joint analyses across multidomain lifestyle trials will allow more detailed subgroup analyses in the future, including analyses of sex differences in intervention efficacy and adherence.

We based our estimates of change in dementia risk on data from the middle-aged observational cohort originally used to develop the CAIDE score [7]. This is because dementia risk estimates in observational studies of older populations may be influenced by reverse causation, i.e., vascular/metabolic factors may be affected by "silent" disease processes. However, because the CAIDE risk score was developed and validated in a midlife population, the estimated risk of dementia is most likely an underestimation in this population of older adults. Ongoing FINGER extended follow-up will provide data on observed dementia incidence, and more accurate risk reduction estimates and evaluation of the CAIDE score as a potential surrogate outcome in lifestyle-based dementia prevention trials [17].

As FINGER targeted at-risk participants from the general population, the importance of potential risk reduction should be interpreted in a public health context. There is currently no direct evidence of costefficacy of dementia prevention interventions, but previous modelling studies have suggested that relatively small risk reductions (0.6-3.2\%) may already be cost-effective [18].

The FINGER participants were recruited from previous population-based studies and they are wellrepresentative of at-risk older adults in Finland [10]. The CAIDE score has been validated in, e.g., diverse population in the US, and therefore also our results may be at least to some extent generalizable to other older at-risk populations. However, the relative importance of modifiable risk factors may differ across populations and over time. In an early prevention trial it is still difficult to estimate the potential clinical significance of the findings. CAIDE risk score can be used as a tool to communicate dementia risk, and to select persons that may benefit from lifestyle interventions. Based on the current results, it can perhaps also be used to track risk factor changes. Novel biomarker assays as well as additional lifestyle and clinical measures may contribute to further development of more sensitive risk scores.

In conclusion, an important area for future developments in dementia prevention would be multifactorial algorithms that estimate both dementia risk and prevention potential and are highly sensitive to capturing change in various risk factors over time. Establishing risk models as surrogate outcomes for dementia development would greatly facilitate assessing the long-term impact of dementia prevention trials.

\section{ACKNOWLEDGMENTS}

The authors wish to thank all participants and staff and members of FINGER study group.

AS received research funding from the European Research Council grant 804371, Academy of Finland (287490, 294061, 319318), Finnish Cultural Foundation, Yrjö Jahnsson Foundation (Finland), Alzheimerfonden and Region Stockholm ALF (Sweden). RA received State research funding (EVO/VTR grants) of Oulu University Hospital and Oulu City 
Hospital (Finland). HS received funding from EU 7th framework collaborative project grant (HATICE), EU Joint Programme - Neurodegenerative Disease Research (MIND-AD), UEF Strategic funding for UEFBRAIN (Finland), and State research Funding (EVO/VTR grants) from Kuopio University Hospital (Finland). MK received research support from the Academy of Finland (317465), Finnish Social Insurance Institution, Finnish Ministry of Education and Culture, Juho Vainio Foundation (Finland), EU Joint Programme - Neurodegenerative Disease Research (MIND-AD and EURO-FINGERS), Alzheimer's Research and Prevention Foundation (US), Alzheimerfonden (Sweden), Swedish Research Council, Center for Innovative Medicine (CIMED) at Karolinska Institutet, Region Stockholm (ALF, NSV), Knut and Alice Wallenberg Foundation (Sweden), Stiftelsen Stockholms sjukhem (Sweden), Konung Gustaf V:s och Drottning Victorias Frimurarstiftelse (Sweden). TN received research funding from EU Joint Programme - Neurodegenerative Disease Research (EURO-FINGERS) and Finnish Cultural Foundation, Juho Vainio Foundation; and Jalmari and Rauha Ahokas Foundation, Finland.

Authors' disclosures available online (https:// www.j-alz.com/manuscript-disclosures/21-0331r1).

\section{REFERENCES}

[1] Winblad B, Amouyel P, Andrieu S, Ballard C, Brayne C, Brodaty H, Cedazo-Minguez A, Dubois B, Edvardsson D, Feldman H, Fratiglioni L, Frisoni GB, Gauthier S, Georges J, Graff C, Iqbal K, Jessen F, Johansson G, Jonsson L, Kivipelto M, Knapp M, Mangialasche F, Melis R, Nordberg A, Rikkert MO, Qiu C, Sakmar TP, Scheltens P, Schneider LS, Sperling R, Tjernberg LO, Waldemar G, Wimo A, Zetterberg H (2016) Defeating Alzheimer's disease and other dementias: A priority for European science and society. Lancet Neurol 15, 455-532.

[2] Tang EY, Harrison SL, Errington L, Gordon MF, Visser PJ, Novak G, Dufouil C, Brayne C, Robinson L, Launer LJ, Stephan BC (2015) Current developments in dementia risk prediction modelling: An updated systematic review. PLoS One 10, e0136181.

[3] Ngandu T, Lehtisalo J, Solomon A, Levalahti E, Ahtiluoto S, Antikainen R, Backman L, Hanninen T, Jula A, Laatikainen T, Lindstrom J, Mangialasche F, Paajanen T, Pajala S, Peltonen M, Rauramaa R, Stigsdotter-Neely A, Strandberg T, Tuomilehto J, Soininen H, Kivipelto M (2015) A 2 year multidomain intervention of diet, exercise, cognitive training, and vascular risk monitoring versus control to prevent cognitive decline in at-risk elderly people (FINGER): A randomised controlled trial. Lancet 385, 2255-2263.

[4] Strandberg T, Levalahti E, Ngandu T, Solomon A, Kivipelto M, for FINGER Study Group (2017) Health-related quality of life in a multidomain intervention trial to prevent cognitive decline (FINGER). Eur Ger Med 8, 164-167.
[5] Kulmala J, Ngandu T, Havulinna S, Levalahti E, Lehtisalo J, Solomon A, Antikainen R, Laatikainen T, Pippola P, Peltonen M, Rauramaa R, Soininen H, Strandberg T, Tuomilehto J, Kivipelto M (2019) The effect of multidomain lifestyle intervention on daily functioning in older people. $J \mathrm{Am}$ Geriatr Soc 67, 1138-1144.

[6] Marengoni A, Rizzuto D, Fratiglioni L, Antikainen R, Laatikainen T, Lehtisalo J, Peltonen M, Soininen H, Strandberg T, Tuomilehto J, Kivipelto M, Ngandu T (2018) The effect of a 2-year intervention consisting of diet, physical exercise, cognitive training, and monitoring of vascular risk on chronic morbidity-the FINGER Randomized Controlled Trial. J Am Med Dir Assoc 19, 355-360.e1.

[7] Kivipelto M, Ngandu T, Laatikainen T, Winblad B, Soininen H, Tuomilehto J (2006) Risk score for the prediction of dementia risk in 20 years among middle aged people: A longitudinal, population-based study. Lancet Neurol 5, 735-741.

[8] Exalto LG, Quesenberry CP, Barnes D, Kivipelto M, Biessels GJ, Whitmer RA (2014) Midlife risk score for the prediction of dementia four decades later. Alzheimers Dement 10, 562-570.

[9] Kivipelto M, Solomon A, Ahtiluoto S, Ngandu T, Lehtisalo J, Antikainen R, Backman L, Hanninen T, Jula A, Laatikainen T, Lindstrom J, Mangialasche F, Nissinen A, Paajanen T, Pajala S, Peltonen M, Rauramaa R, StigsdotterNeely A, Strandberg T, Tuomilehto J, Soininen H (2013) The Finnish Geriatric Intervention Study to Prevent Cognitive Impairment and Disability (FINGER): Study design and progress. Alzheimers Dement 9, 657-665.

[10] Ngandu T, Lehtisalo J, Levälahti E, Laatikainen T, Lindström J, Peltonen M, Solomon A, Ahtiluoto S, Antikainen R, Hänninen T, Jula A, Mangialasche F, Paajanen T, Pajala S, Rauramaa R, Strandberg T, Tuomilehto J, Soininen H, Kivipelto M (2014) Recruitment and baseline characteristics of participants in the Finnish Geriatric Intervention Study to Prevent Cognitive Impairment and Disability (FINGER) - a randomized controlled lifestyle trial. Int $J$ Environ Res Public Health 11, 9345-9360.

[11] Morris JC, Heyman A, Mohs RC, Hughes JP, van Belle G, Fillenbaum G, Mellits ED, Clark C (1989) The Consortium to Establish a Registry for Alzheimer's Disease (CERAD). Part I. Clinical and neuropsychological assessment of Alzheimer's disease. Neurology 39, 1159-1165.

[12] Hanninen T, Pulliainen V, Sotaniemi M, Hokkanen L, Salo J, Hietanen M, Pirttila T, Poyhonen M, Juva K, Remes A, Erkinjuntti T (2010) [Early detection of cognitive changes in memory diseases: New cut-off scores for the Finnish version of CERAD neuropsychological battery]. Duodecim 126, 2013-2021.

[13] Folstein MF, Folstein SE, McHugh PR (1975) "Mini-mental state". A practical method for grading the cognitive state of patients for the clinician. J Psychiatr Res 12, 189-198.

[14] Solomon A, Turunen H, Ngandu T, Peltonen M, Levalahti E, Helisalmi S, Antikainen R, Backman L, Hanninen T, Jula A, Laatikainen T, Lehtisalo J, Lindstrom J, Paajanen T, Pajala S, Stigsdotter-Neely A, Strandberg T, Tuomilehto J, Soininen H, Kivipelto M (2018) Effect of the Apolipoprotein $\mathrm{E}$ genotype on cognitive change during a multidomain lifestyle intervention: A subgroup analysis of a randomized clinical trial. JAMA Neurol 75, 462-470.

[15] Braunholtz DA, Edwards SJ, Lilford RJ (2001) Are randomized clinical trials good for us (in the short term)? Evidence for a "trial effect". J Clin Epidemiol 54, 217-224. 
[16] Waters L, Reeves M, Fjeldsoe B, Eakin E (2012) Control group improvements in physical activity intervention trials and possible explanatory factors: A systematic review. $J$ Phys Act Health 9, 884-895.

[17] Buyse M, Molenberghs G, Paoletti X, Oba K, Alonso A, Van der Elst W, Burzykowski T (2016) Statistical evaluation of surrogate endpoints with examples from cancer clinical trials. Biom J 58, 104-132.

[18] Handels R, Wimo A (2019) Challenges and recommendations for the health-economic evaluation of primary prevention programmes for dementia. Aging Ment Health 23, 53-59. 